\title{
Letter to the Editor Regarding "Preoperative Digital Subtraction Angiography in Incidental Unruptured Intracranial Aneurysms"
}

\author{
Ajay Malhotra ${ }^{1}(\mathrm{D}) \cdot \mathrm{Xiao}_{\mathrm{Wu}}{ }^{1} \cdot$ Long Tu $^{1} \cdot \mathrm{Kimberly}$ Seifert ${ }^{1}$ \\ Received: 7 May 2018 / Accepted: 29 May 2018 / Published online: 27 June 2018 \\ c) Springer-Verlag GmbH Germany, part of Springer Nature 2018
}

\section{Dear Editor,}

We would like to commend the authors Herzberg et al. for their study assessing the role of preoperative digital subtraction angiography (DSA) in unruptured intracranial aneurysms (UIAs) [1]; however we have some questions and comments about the study.

The authors conclude that four-vessel angiography can be indicated in patients with multiple aneurysms because 4 out of 5 UIA missed on magnetic resonance imaging (MRI) in this study were in patients with multiple aneurysms; however, as the authors state, between $20 \%$ and $27 \%$ of all patients may have multiple UIAs. That would still be a significant proportion of patients with UIAs. All the UIAs missed on MRA were very small $(\leq 3 \mathrm{~mm})$. We would like the authors to comment if these could be seen on the MRA in retrospect. The authors mention positive bias towards MRA in the limitations; however, the same bias applies to DSA, as the person performing DSA was aware of the MRA findings: the assumption here is that DSA is perfect.

The implication of these additional findings on DSA is not clear. This is partly because the natural history of these small UIAs is not well understood [2]. Out of five aneurysms missed on MRA in this study four were not treated but received surveillance imaging. The guidelines do not specify the frequency and duration of imaging followup [3]. There is also significant heterogeneity in practice re-

\author{
Ajay Malhotra \\ ajay.malhotra@yale.edu \\ Xiao Wu \\ xiao.wu@yale.edu \\ Long Tu \\ long.tu@yale.edu \\ Kimberly Seifert \\ kimberly.seifert@yale.edu
}

1 Department of Radiology and Biomedical Imaging, Yale University School of Medicine, Tompkins East 2, 333 Cedar St, New Haven, CT 06520-8042, USA garding the modality for surveillance imaging, the criteria used for growth and criteria used for treatment of UIAs [4]. Routine imaging surveillance may not be cost-effective or add benefits in the case of small and very small aneurysms [5]. The fact that these were missed on MRA raises further questions about the utility of follow-up imaging, and its reliability in detecting growth or change of geometry that might suggest treatment.

We would also request the authors to specify the proportion of small and very small aneurysms in their cohort of 106 patients with 134 aneurysms. Is it correct to assume that all the patients were treated/attempted to be treated since DSA was performed for UIAs?

Conflict of interest A. Malhotra, X. Wu, L. Tu and K. Seifert declare that they have no competing interests.

\section{References}

1. Herzberg M, Forbrig R, Schichor C, Brückmann H, Dorn F. Preoperative digital subtraction angiography in incidental unruptured intracranial aneurysms : How much is too much? Clin Neuroradiol. 2018; https://doi.org/10.1007/s00062-018-0689-x.

2. Malhotra A, Wu X, Forman HP, Grossetta Nardini HK, Matouk CC, Gandhi D, Moore C, Sanelli P. Growth and rupture risk of small unruptured intracranial aneurysms: A systematic review. Ann Intern Med. 2017;167:26-33.

3. Thompson BG, Brown RD Jr, Amin-Hanjani S, Broderick JP, Cockroft KM, Connolly ES Jr, Duckwiler GR, Harris CC, Howard VJ, Johnston SC, Meyers PM, Molyneux A, Ogilvy CS, Ringer AJ, Torner J; American Heart Association Stroke Council, Council on Cardiovascular and Stroke Nursing, and Council on Epidemiology and Prevention; American Heart Association; American Stroke Association. Guidelines for the management of patients with unruptured intracranial aneurysms: A guideline for healthcare professionals from the american heart association/american stroke association. Stroke. 2015;46:2368-400.

4. Malhotra A, Wu X, Geng B, Hersey D, Gandhi D, Sanelli P. Management of small unruptured intracranial aneurysms: a survey of neuroradiologists. AJNR Am J Neuroradiol. 2018;39:875-80.

5. Malhotra A, Wu X, Forman HP, Matouk CC, Gandhi D, Sanelli P. Management of tiny unruptured intracranial aneurysms: A comparative effectiveness analysis. JAMA Neurol. 2018;75:27-34. 